Metals and Ceramics Division

CRADA FINAL REPORT

FOR CRADA NO. ORNL00-0598

\title{
SAFE USE LIMITS FOR ADVANCED FERRITIC STEELS IN ULTRA-SUPERCRITICAL POWER BOILERS
}

\author{
Michael Gold \\ James Tanzosh \\ Babcock \& Wilcox Company.
}

R. W. Swindeman, P. J. Maziasz, and M. L. Santella

Oak Ridge National Laboratory

\author{
Prepared by \\ Oak Ridge National Laboratory \\ Oak Ridge, Tennessee 37831 \\ Managed by \\ UT-BATTELLE, LLC \\ For the \\ U.S. Department of Energy \\ Under contract DE-AC05-00OR22725
}

Approved for Public Release

Unlimited Distribution

This research was supported through a CRADA with McDermott Technologies, Inc., sponsored by U.S. Department of Energy, Associate Secretary for Office of Fossil Energy Advanced Research under contract DE-AC05-00OR22725 with Oak Ridge National Laboratory, managed by UT-Battelle, LLC. 


\begin{abstract}
In 2000, a Cooperative Research and Development Agreement (CRADA) was undertaken between the Oak Ridge National Laboratory (ORNL) and the Babcock \& Wilcox Company to examine the databases for advanced ferritic steels and determine the safe limits for operation in supercritical steam power boilers. The materials of interest included the vanadium-modified 9-12\% Cr steels with 1-2\% Mo or W. The first task involved a review of pertinent information and the down-selection of a steel of special interest. The long-time database for $9 \mathrm{Cr}-1 \mathrm{Mo}-\mathrm{V}$ steel was found to be most satisfactory for the examinations, and this steel was taken to be representative of the group. The second task involved the collection of aged and service exposed samples for metallurgical and mechanical testing. Here, aged samples to 75,000 hours, laboratory-tested samples to 83,000 hours, and service-exposed sample with up to 143,000 hours exposure were collected. The third task involved mechanical testing of exposed samples. Creeprupture testing to long times was undertaken. Variable stress and temperature testing was included. Results were compared against the prediction of damage models. These models seemed to be adequate for life prediction. The fourth task involved the metallurgical examination of exposed specimens. Changes in microstructure were compared against published information on the evolution of microstructures in $9 \mathrm{Cr}-\mathrm{Mo}-\mathrm{V}$ steels and the results were found to be consistent with expectations. The fifth task involved a survey of steam and fireside corrosion. Data from the service-exposed tubing was examined, and a literature survey was undertaken as part of an activity in support of ultra-supercritical steam boiler technology. The corrosion study indicated some concerns about long-time fireside corrosion and suggested temperature limits were needed for corrosive coal ash conditions.
\end{abstract}

\title{
Objectives
}

The objectives of the Cooperative Research and Development Agreement (CRADA) between UT-Battelle, LLC, (Contractor) and Babcock \& Wilcox Technologies, Inc. (Participant) was to use state-of-the-art methods of material evaluation and analysis to determine the safe use limits for advanced ferritic steels that are candidates for construction of fossil power supercritical and ultra-supercritical boiler superheater components. It was recognized a priori that these highly complex steels undergo significant microstructural alteration, steam corrosion, and fireside wastage at the service conditions for which they are envisioned, but no practical alternative alloys are available. Since the development of optimized compositions, fabrication technologies, and operating limits have a major impact on the projection of capital and operating costs for the advanced steam cycle power plants, an accurate assessment based on knowledge of long-time material performance was judged to be essential to the development process.

\section{Benefits}

The CRADA was expected to lend credibility to a technology that significantly increases in the efficiency of fossil fuels combustion with concomitant reductions in $\mathrm{CO}_{2}$ emissions. Increasing the temperature of operation for advanced ferritic steel structural components is expected to increase plant efficiencies to substantially over $40 \%$ for pulverized coal combustion. If the lifeprediction methodology can be shown to reliably establish the operating limits, full use can be 
made of the potential of third and fourth generation ferritic steels. Plants can be designed that lower heat rates and raise efficiencies to well above $45 \%$.

\section{Work Performed}

The scope of the CRADA encompassed both analytical and experimental work organized into five tasks. The five tasks comprised Phase 1 that covered the entire period of the 2-year CRADA effort. At the close of Phase 1, an evaluation was made of the need to extend the CRADA to Phase II, which involved additional materials and longer testing times.

\section{Task 1 - Information Review}

A detailed program plan was developed that consisted of: (1) The selection 9Cr-1Mo-V (P91, T91) steel as the principal focus for the work [Other steels such as 9Cr-1.5W-V (P92, T92), 12Cr-1.5W-V (P122, T122), 12Cr-2W-V (HCM12), 9Cr-1W-V (E911), and 2 1/4Cr-W-V (T23, P23)] were retained an a second priority basis; (2) The collection of high-temperature design data for grade 91; (3) The review of published evaluations bearing on the issue of long-time temperature limits; (4) The identification of critical metallurgical degradation mechanisms; and (5) The review of steam and fireside corrosion experience. Some aspects of the Task 1 activity are included in a recent publication [1].

\section{$\underline{\text { Task } 2 \text { - Sample Collection and Studies }}$}

Creep-rupture data for plate, tubing, and piping products were collected. Samples included three heats of plate materials that were laboratory-aged to as long as 75,000 hours at five temperatures. These conditions are shown in Table 1. Aging temperatures ranged to as high as $704^{\circ} \mathrm{C}$. Another group of samples was from discontinued laboratory tests. These are listed in Table 2. Here, it may be seen that exposure times extended to beyond 100,000 hours in some cases although the temperatures are mostly $538^{\circ} \mathrm{C}$ and below. A third group of test samples were taken from tubing removed after long-time service in two supercritical power boilers. The service times included 30,000 hours, 116,000 hours and 143,000 hours.

Table 1. Range of temperatures and times covered by aging three heats of $9 \mathrm{Cr}-1 \mathrm{Mo}-\mathrm{V}$ steel

\begin{tabular}{|c|c|c|c|c|c|}
\hline TEMPERATURE & $5,000 \mathrm{~h}$ & $10,000 \mathrm{~h}$ & $25,000 \mathrm{~h}$ & $50,000 \mathrm{~h}$ & $75,000 \mathrm{~h}$ \\
\hline $\operatorname{deg} \mathrm{C}$ & & & & & \\
\hline 482 & $\mathrm{~A}, \mathrm{C}$ & $\mathrm{A}, \mathrm{C}$ & $\mathrm{A}, \mathrm{C}$ & $\mathrm{C}$ & $\mathrm{C}$ \\
\hline 538 & $\mathrm{~A}, \mathrm{C}$ & $\mathrm{A}, \mathrm{C}$ & $\mathrm{A}, \mathrm{C}$ & $\mathrm{C}$ & $\mathrm{C}$ \\
\hline 593 & $\mathrm{~A}, \mathrm{C}$ & $\mathrm{A}, \mathrm{C}$ & $\mathrm{C}$ & $\mathrm{C}$ & $\mathrm{C}$ \\
\hline 649 & $\mathrm{~A}, \mathrm{C}$ & $\mathrm{A}, \mathrm{B}, \mathrm{C}$ & $\mathrm{A}, \mathrm{B}, \mathrm{C}$ & $\mathrm{B}, \mathrm{C}$ & $\mathrm{B}, \mathrm{C}$ \\
\hline 704 & $\mathrm{~A}, \mathrm{C}$ & $\mathrm{A}, \mathrm{B}, \mathrm{C}$ & $\mathrm{B}, \mathrm{C}$ & & \\
\hline
\end{tabular}

Note: A, B, C denote three different heats 
Table 2. Specimens from discontinued laboratory tests

\begin{tabular}{|c|c|c|c|c|c|c|}
\hline Test No. & Product & Heat Code & Condition & Temp. ${ }^{\circ} \mathrm{C}$ & Stress ksi & Time h \\
\hline & & & & & & \\
\hline 22502 & wrought & 148 & nt & 538 & 28 & 100495 \\
\hline 24079 & wrought & 176 & $25 \mathrm{k} / 593 \mathrm{C}$ & 593 & 16 & 37508 \\
\hline 24357 & wrought & 176 & $25 \mathrm{k} / 538 \mathrm{C}$ & 538 & 30 & 32212 \\
\hline 24073 & wrought & 394 & $25 \mathrm{k} / 593 \mathrm{C}$ & 593 & 16 & 37892 \\
\hline 20824 & & 53494 & nt & 538 & 30 & 6258 \\
\hline 24752 & wrought & 176 & nt & 482 & 40 & 84147 \\
\hline $\mathbf{2 4 5 7 7}$ & wrought & $\mathbf{3 9 4}$ & nt & $\mathbf{5 3 8}$ & $\mathbf{2 4}$ & $\mathbf{8 3 8 0 3}$ \\
\hline 24359 & wrought & 176 & $25 \mathrm{k} / 538$ & 538 & 27 & 32109 \\
\hline 25409 & weld & pc110 & 760 pwht & 538 & 25.5 & 16585 \\
\hline 25604 & weld & pc111 & 760 pwht & 593 & 17 & 10727 \\
\hline 23507 & cast & 69 & as-cast & 482 & 35 & 59408 \\
\hline 24007 & cast & 603 & as-cast & 538 & 20 & 40051 \\
\hline 24363 & weld & pc110 & 760 pwht & 538 & 26 & 80256 \\
\hline 24279 & weld & pc129 & 732 pwht & 538 & 30 & 82058 \\
\hline 25403 & weld & pc110 & 760 pwht & 538 & 27 & 16746 \\
\hline 24899 & wrought & 148 & nt & 538 & 24 & 82060 \\
\hline 21822 & wrought & 394 & nt & 427 & 60 & 132539 \\
\hline 24772 & wrought & 148 & nt & 482 & 40 & 83126 \\
\hline 25410 & weld & pc111 & 760 pwht & 538 & 26 & 16439 \\
\hline 24351 & wrought & 394 & $25 \mathrm{k} / 538 \mathrm{C}$ & 538 & 30 & 32460 \\
\hline 23698 & wrought & 394 & nt & 427 & 55 & 106523 \\
\hline $\mathbf{2 4 8 2 0}$ & wrought & $\mathbf{3 8 3}$ & nt & $\mathbf{5 3 8}$ & $\mathbf{2 4}$ & $\mathbf{8 2 6 9 7}$ \\
\hline 24749 & wrought & 394 & nt & 482 & 40 & 83491 \\
\hline 24995 & wrought & pc163 & 760 pwht & 593 & 11 & 79009 \\
\hline 25535 & weld & pc111 & 760 pwht & 538 & 24 & 13701 \\
\hline 20842 & wrought & 5349 & nt & 538 & 26 & 132647 \\
\hline $\mathbf{2 7 4 0 3}$ & wrought & $\mathbf{3 8 3}$ & nt & $\mathbf{5 3 8}$ & $\mathbf{3 0}$ & $\mathbf{4 0 2 2 0}$ \\
\hline $\mathbf{2 4 8 4 7}$ & wrought & $\mathbf{1 7 6}$ & nt & $\mathbf{5 3 8}$ & $\mathbf{2 4}$ & $\mathbf{8 2 8 6 0}$ \\
\hline 24118 & & 582 & nt & 593 & 16 & 96544 \\
\hline 25401 & weld & pc111 & 760 pwht & 538 & 28 & 16941 \\
\hline $\mathbf{2 7 3 8 6}$ & wrought & $\mathbf{3 8 3}$ & $\mathbf{q t}$ & $\mathbf{5 3 8}$ & $\mathbf{3 0}$ & $\mathbf{4 0 8 7 1}$ \\
\hline
\end{tabular}

Table 3. Service conditions for superheater tubing

\begin{tabular}{|c|c|c|c|}
\hline BOILER & STEAM TEMP.(C) & PRESSURE (Mpa) & SERVICE TIME (h) \\
\hline & & & \\
\hline $\mathrm{A}$ & 540 & 14 & 30,500 \\
\hline $\mathrm{B}$ & 567 & 12.7 & 116,000 \\
\hline $\mathrm{B}$ & 567 & 12.7 & 143,000 \\
\hline
\end{tabular}




\section{$\underline{\text { Task } 3 \text { - Creep-Rupture Evaluations }}$}

The historic database for $9 \mathrm{Cr}-1 \mathrm{Mo}-\mathrm{V}$ steel was collected and analyzed. Creep rupture data, for example, were collected and correlated on the basis of the Larson-Miller time-temperature parameter (LMP). The results are summarized in Fig. 1. Here, the stress is plotted against the parameter LMP value for nearly 1000 test data produced in the U.S., Japan, and Europe. The parametric constant was taken as 30 . The overall trend of the data suggests a downward curvature with increasing LMP. The concern regarding operating limits for $9 \mathrm{Cr}-1 \mathrm{Mo}-\mathrm{V}$ steel includes the impact of the rapid fall off in strength at the highest temperatures or longest times. Data at the upper limit for $9 \mathrm{Cr}-1 \mathrm{Mo}-\mathrm{V}$ steel are relatively few. At $593^{\circ} \mathrm{C}$ the allowable design stress is $70 \mathrm{MPa}$ (10.3 ksi) for section thicknesses of $75 \mathrm{~mm}$ (3 inches) or less. This stress is near the limit of the database. At $649^{\circ} \mathrm{C}$ the allowable stress is $30 \mathrm{MPa}(4.3 \mathrm{ksi})$. At this stress, there are few data to support the extrapolated stress. To produce data at the allowable stress limit, laboratory testing must be performed at $704^{\circ} \mathrm{C}$ where oxidation effects are a problem.

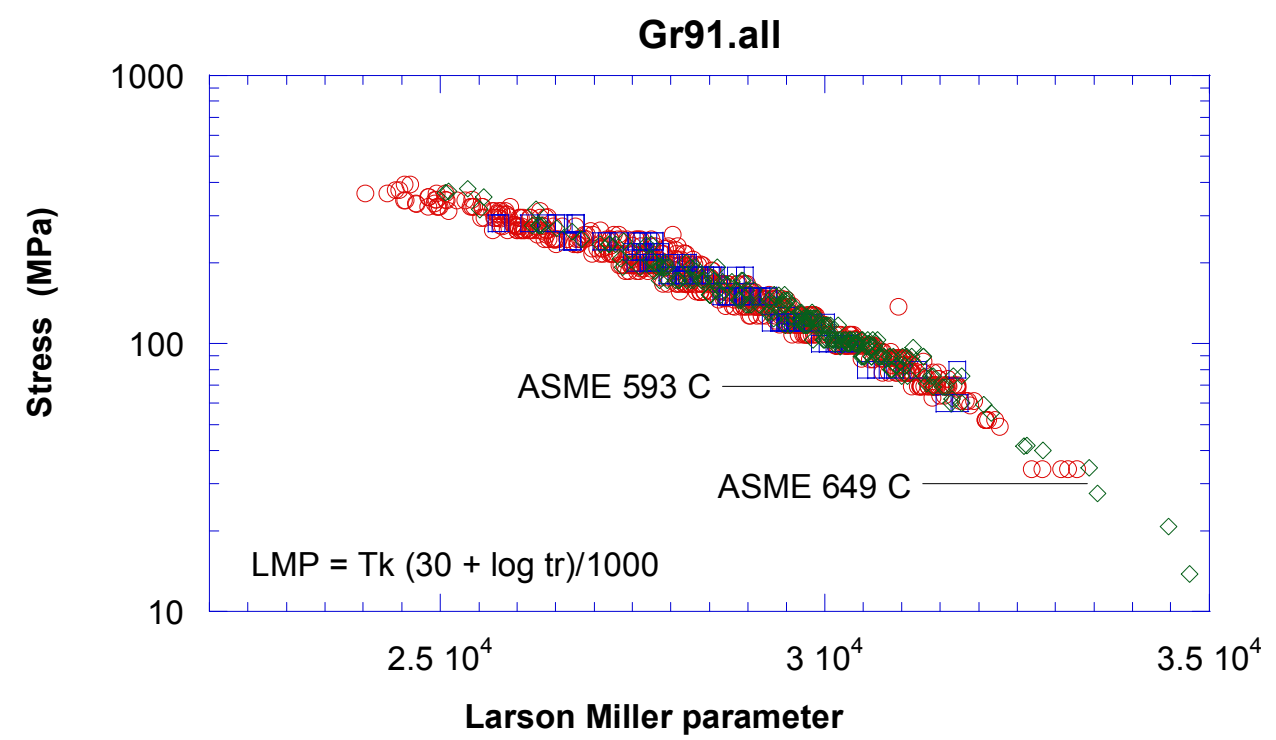

Fig. 1. Stress versus Larson Miller parameter for the $9 \mathrm{Cr}-1 \mathrm{Mo}-\mathrm{V}$ steel database

Thermal aging for long times at the higher temperatures was expected to simulated long-time service conditions at lower temperatures. Thus, 10,000 to 25,000 hours of thermal aging at $649^{\circ} \mathrm{C}$ was judged to be representative of very long-time service at $593^{\circ} \mathrm{C}$ and similar times at $704^{\circ} \mathrm{C}$ were judged to be representative of very long-times at $649^{\circ} \mathrm{C}$. Creep-rupture testing of materials aged at conditions listed in Table 1 produced shorter rupture lives than as-normalized and tempered (NT) materials but no test data indicated that the strength of long-time aged materials fell below the allowable strengths for $9 \mathrm{Cr}-1 \mathrm{Mo}-\mathrm{V}$ steel for the test temperature. Typical trends are shown in Fig. 2. The plot includes some of the more than 90 creep-rupture tests performed on aged material. The results are compared to the stress allowables from ASME Sect. II, Part D. It is clear that more testing is needed at stress below $100 \mathrm{MPa}$, but the CRADA ended before this testing could be completed. Some aspects of the aging work were presented in 2000 [2]. 


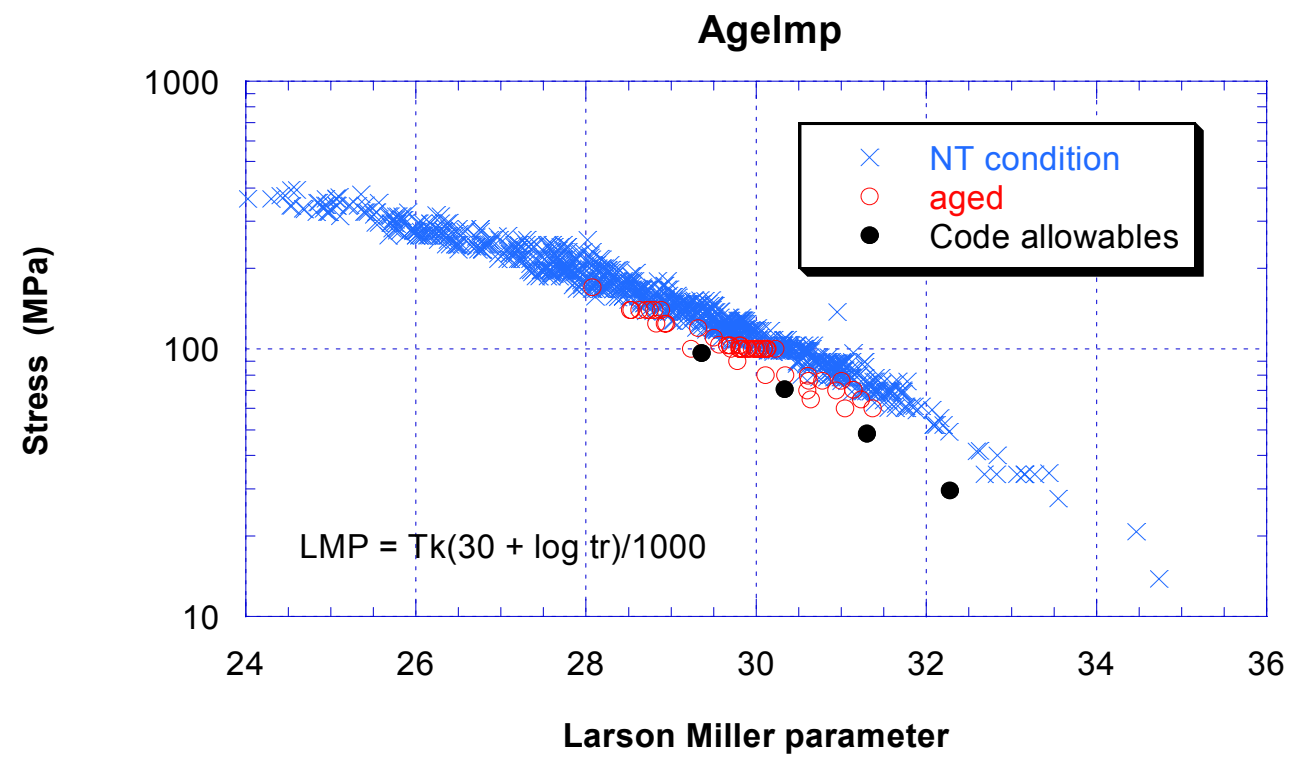

Fig. 2. Comparison of rupture data for aged material with the as-NT database and ASME allowables on the bases of the Larson Miller parameter

Several specimens from the list in Table 2 were tested at $600^{\circ} \mathrm{C}$ and $100 \mathrm{MPa}$. The specimens are identified by the bold printed lines in the table. All exposures were at a relatively low temperature, $538^{\circ} \mathrm{C}$, but long times were involved. For the test condition of $600^{\circ} \mathrm{C}$ and $100 \mathrm{MPa}$, an unexposed specimen would survive more than 30,000 hours. Significant damage was judged to be present in some of the exposed specimens and this damage would produce shorter life. No specimens failed at the time the CRADA ended.

Specimens from the service-exposed boiler tubing were tested at a variety of stresses and temperatures ranging from 550 to $700^{\circ} \mathrm{C}$. Stresses were in the range of 80 to $170 \mathrm{MPa}$. Similar to the behavior of the thermally aged specimens, the creep rupture life was reduced by service exposure. Generally, the specimens tested at the higher temperatures showed less loss in life than specimens tested at the lower range of temperatures. Again, the long-time, low stress testing was not completed before the CRADA ended.

Regardless of aging, prior creep, or service exposure conditions, the creep rate versus rupture life correlation was identical. This correlation, known as the Monkman-Grant plot, is shown in Fig. 3. If this plot holds for the high-temperature, low-stress condition then use can be made in estimating life from the shorter time testing required to establish the minimum creep rate. Unfortunately, one can only be sure that the correlation holds by actually running the long-time rupture test. 


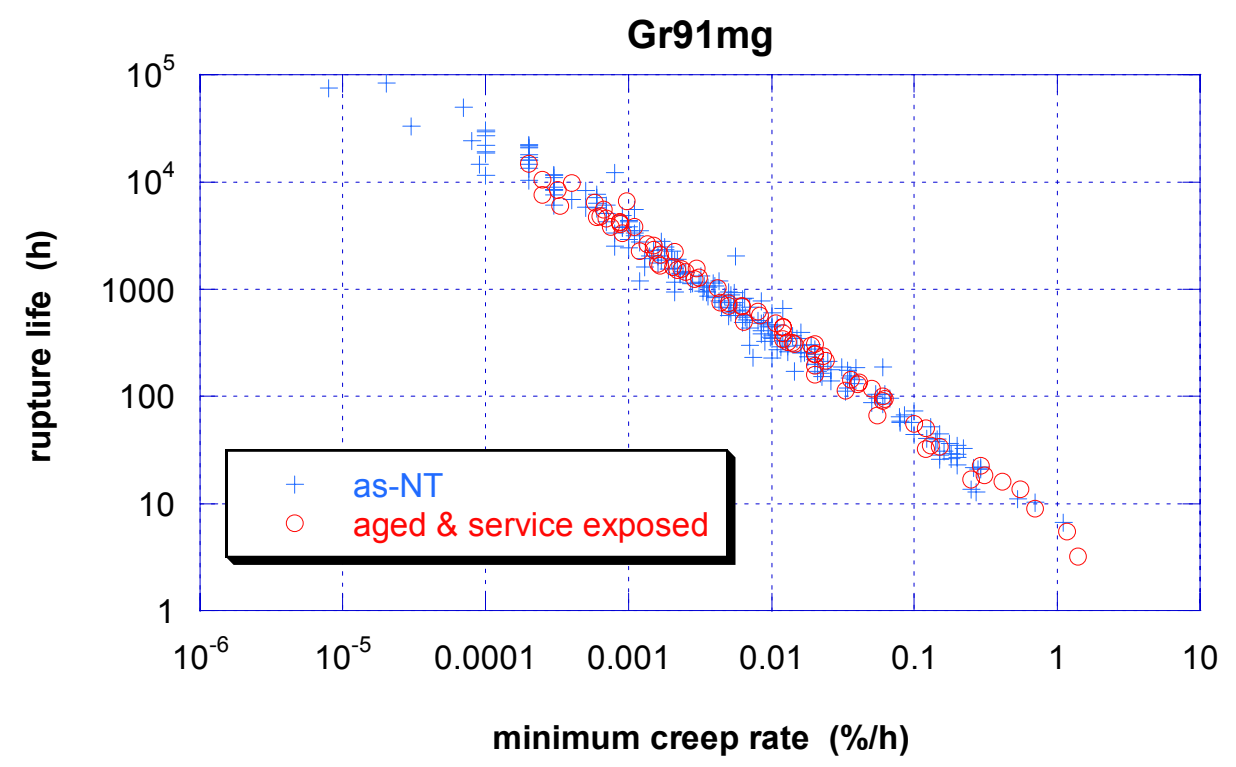

Fig. 3. Comparison of the Monkman-Grant trend for as-NT, aged, and service exposed materials

As the CRADA progressed, the performance of weldments in the advanced ferritic steels took on importance. A number of issues arose that related to welding technology and the subsequent long-time performance of welded components. The Participant delivered a thick-section weldment to the contractor. This material was used to examine a number of important issues. Included were: (1) the effect of nickel plus manganese content on the critical transformation temperatures such as the martensitic start and finish and the $A_{c 1}$ transformation temperature, (2) the effect of retained austenitic on the performance after post-weld heat treatment, (3) the effect of post weld heat treatment temperature on creep-rupture, and (4) the effect of renormalization on the creep rupture of weldments. Some aspects of this work were included in a recent publication [3].

\section{Task 4 - Metallurgical Investigation}

Metallurgical investigation of aged, mechanically tested, and service-exposed samples were undertaken. Optical microscopy and scanning electron microscopy (SEM) were performed. General features that were examined included cracking modes, grain stability, and precipitate characteristics. Transmission electron microscopy (TEM) and analytical electron microscopy (AEM) were performed. The investigation produced results that were consistent with previously published results. The long-time exposure at high temperature results in evolution of microstructure to a softer, less creep-resistant condition.

\section{Task 5 - Oxidation and Corrosion Behavior Study}

The fireside and steamside corrosion of the exposed superheater tubing were compared to literature models and found to be more-or-less consistent with these models (3). Literature reviews, plant experiences, and results from parallel studies that produced experimental results were incorporated into an analysis and assessment of the operating limits imposed by corrosion. 
These results were incorporated into an assessment performed a part of the ultra-supercritical steam boiler project supported by the DOE (4).

\section{Inventions}

The $9 \mathrm{Cr}-1 \mathrm{Mo}-\mathrm{V}$ steel was developed under support by the U.S. Department of Energy (DOE) for use on nuclear and fossil energy programs. A second steel, 9Cr-W-V-Ta, was also developed under DOE support for application in fusion energy programs. No new inventions resulted from the work on this CRADA.

\section{Commercialization Possibilities}

The steels investigated in this CRADA are being used extensively in the U.S. for both new and replacement functions. Further extension of the application for these steels to longer times or higher will depend on the results of collaborative efforts now underway.

\section{Plans for Future Collaboration}

Collaboration is underway between Babcock \& Wilcox, ORNL and a number of other companies to continue the research on the service limits for the advanced ferritic steels. Some of the testing initiated under this CRADA will be continued and expanded to resolve the issues important to the production of more efficient power generation.

\section{Conclusions}

The upper temperature limit for $9 \mathrm{Cr}-1 \mathrm{Mo}-\mathrm{V}$ steel is more determined by steamside and fireside corrosion than by long-time creep rupture strength. Although the strength degrades with continued exposure there is no evidence that the long-time strength falls below the stress allowables currently listed in ASME Sect. II, Part D. However, further evaluation of creep behavior at low stress is needed to fully understand the damage accumulation mechanisms at conditions typical of component operation. This is especially true for components that are expected to operate at $600^{\circ} \mathrm{C}$ and above.

\section{Acknowledgements}

Much of the material collected and aging was undertaken under the supervision of C. R. Brinkman and V. K. Sikka of the Metals and Ceramics Division. The assistance of R. R. Judkins, Manager of Fossil Energy Programs at ORNL, and F. V. Damiano of UT-Battelle, LLC contracts is appreciated. 


\section{References}

1. R. W. Swindeman, M. L. Santella, P. J. Maziasz, B. W. Roberts, and K. Coleman, "Issues in Replacing Cr-Mo Steels and Stainless Steels with 9Cr-1Mo-V Steel," paper presented at the $7^{\text {th }}$ International Conference on the Operation of Pressure Equipment, Carlton Hotel, Sydney, Australia, April 2-4, 2003.

2. R. W. Swindeman, P. J. Maziasz, and C. R. Brinkman, "Aging Effects on the CreepRupture of 9Cr-1Mo-V Steel," paper published in the proceedings of the 2000 International Joint Power Generation Conference, Miami Beach, Florida, July 23-26, 2000

3. M. L. Santella, R. W. Swindeman, R. W. Reed, and J. M. Tanzosh, "Martensite Transformation, Microstructure, and Creep Strength of 9Cr-1Mo-V Steel Weld Metal,” pp. 713718 in Proceedings of the $6^{\text {th }}$ International Conference on Trends in Welding Research, ASM International, Materials Park, Ohio, 2003.

4. J. Sarver, R. Viswanathan, and S. Mohamed, Boiler Materials for Ultra Supercritical Coal Power Plants-Task 3, Steamside Oxidation of Materials, NETL/DOE, 2003, USC T-5, Electric Power Research Institute, Palo Alto, CA 94304 (June 2003). 


\section{INTERNAL DISTRIBUTION}

1. P. A. Carpenter, 4500 N, 6269

2. P. J. Hadley, 4500S, 6161

3. D. R. Hamrin, 6011,6254

4. R. R. Judkins, 4508, 6084

5. E. Lara-Curzio, 4515, 6069

6. P. J. Maziasz, 4500S, 6115

7. T. M. Rosseel, 4500S, 6161

8. M. L. Santella, 4508, 6096

9. R. W. Swindeman, 4500S, 6155

10. K. M. Wilson, 111B UNV, 6499

11. I. G. Wright, $4500 \mathrm{~S}, 6156$

12. DOE, WFO, 1000,6396

\section{EXTERNAL DISTRIBUTION}

13. Fred Glaser, Portfolio Manager, Department of Energy, Fossil Energy, Office of Advanced Research, FE-72, 19901 Germantown Road, Germantown, MD 20585

14. M. Gold, Gold Metallurgical Services, LLC, 588 Eddy Lane, North Benton, OH 444499735

15. V. Udaya S. Rao, U.S. Department of Energy, National Energy Technology Laboratory (NETL-PGH), 626 Cochrans Mill Road, Pittsburgh, PA 15236-0940

16. Richard B. Read, U. S. Department of Energy, National Energy Technology Laboratory, (NETL-PGH), 626 Cochrans Mill Road, Pittsburgh, PA 15236-0940

17. Robert R. Romanowsky, Jr., U.S. Department of Energy, National Energy Technology Laboratory (NETL-MGN), 3610 Collins Ferry Road, Morgantown, WV 26505-0880

18. Marvin I. Singer, 4G-052/FORS, U.S. Department of Energy, Headquarters, Forrestal, 1000 Independence Avenue, S.W., Washington, DC 20585

19. J. M. Tanzosh, Babcock \& Wilcox, 20 Van Buren Avenue, P. O. Box 351, BVS03B, Barberton, $\mathrm{OH}$ 44203-3585 